\title{
Space Flight Resource Management Training for International Space Station Flight Controllers
}

\author{
William S. O'Keefe \\ United Space Alliance LLC \\ Houston, Texas, USA \\ $281-785-1704$ \\ William.s.okeefe@usa-spaceops.com \\ $7^{\text {th }}$ Global Congress on Process Safety \\ March 13-17, 2011
}




\section{Overview}

- Short summary of Space Station SFRM skills

- How five Lessons Learned are being implemented

- Status of SFRM training in Mission Operations Directorate at the Johnson Space Center 


\section{Our Team Skills Model}

Communication

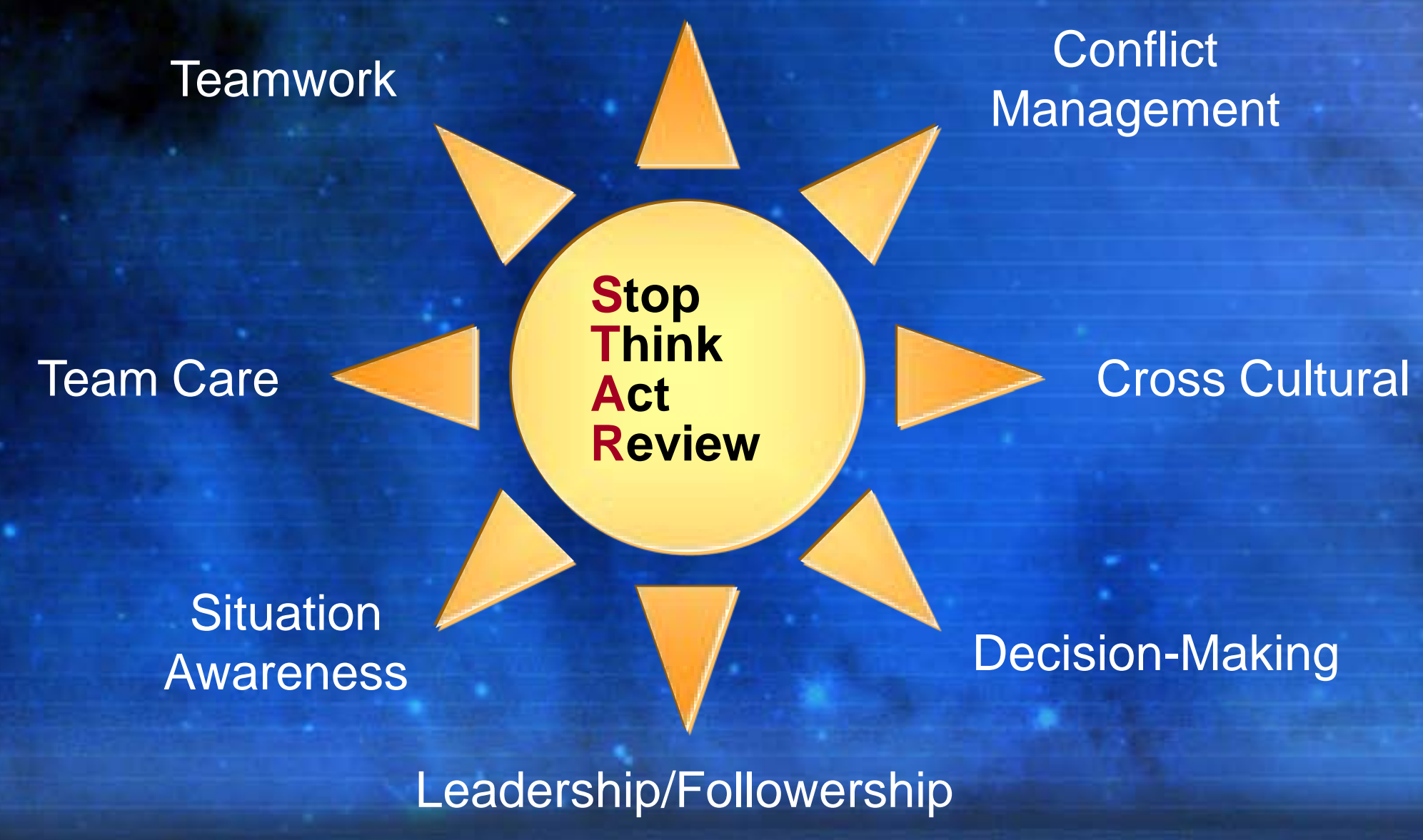




\section{Lessons Learned about SFRM Training}

\section{SFRM}

- is an integrated set of skills

- must be used daily

- must be embedded in technical training

- must be trained formally and learned informally

- must be learned from senior flight controller mentors 


\section{SFRM is an Integrated Set of Skills}

- Each skill affects and is affected by the other 7 skills

- Failure to do any skill properly may result in a failed team effort 


\section{SFRM Used Daily}

- If you use SFRM skills

- At daily status meetings,

- When making routine decisions, and

- When you don't think SFRM is required

- You don't put links in an error chain

- That might eventually result in an incident that requires 'time critical' SFRM 


\section{SFRM Embedded in Technical Training}

- SFRM training must be

- Introduced in the full mission and team context

- Introduced early

- Reinforced continually

- When a flight controller learns a procedure, s/he also learns

- How to assess the situation

- What factors dictate if/when the procedure is executed

- What decisions must be made

- To whom to talk, about what and how

- How to resolve conflicts 


\section{SFRM Trained Formally, Learned Informally}

- Formal training is the lessons in the training programs

- Informal learning is through observations, practice and talking to others

- To take advantage of informal learning, we developed guides for

- New Flight Controllers

- Mentors 


\section{SFRM Learned from Senior Mentors}

- Senior Flight Controllers bring their experience to provide the full mission and team context

- How 'real life' experiences are subtly different from training and from each other

- How mistakes happen, how they are resolved and what are the lessons learned 


\section{Status of SFRM Training in JSC MOD}

- Training includes both SFRM-dedicated lessons and SFRM training embedded into technical lessons

- Goal is to reduce certification times by $50 \%$ and integrated simulations by $75-90 \%$

- SFRM is practiced, evaluated and debriefed in part task trainers and full-task simulation lessons

- SFRM model and training are constantly being evaluated against student/ management feedback, best practices from industry/ military, and latest research 